\title{
GERMINAÇÃO DE SEMENTES DE FÁFIA: INFLUÊNCIA DA ÉPOCA DE COLHEITA, CONDICIONAMENTO TÉRMICO E ARMAZENAMENTO
}

\author{
Ana Cláudia Pacheco ${ }^{1}$, Ceci Castilho Custódio ${ }^{1}$, Rodolfo Andrade Catisti ${ }^{2}$, Renan Bravo Pimenta ${ }^{2}$ \\ ${ }^{1}$ Docente do Programa de Pós-Graduação em Agronomia - UNOESTE - Presidente Prudente, SP. ${ }^{2}$ Curso de Agronomia - UNOESTE. \\ E-mail: anaclau@unoeste.br.
}

\section{RESUMO}

A espécie medicinal Pfaffia glomerata (Spreng.) Pedersen é conhecida popularmente como fáfia ou "ginseng brasileiro", devido ao formato de suas raízes. Uma vez que a espécie é silvestre e existe interesse comercial pela mesma, os estudos sobre as qualidades fisiológica e física das sementes, bem como informações no que diz respeito à germinação, tornam-se necessários. Foram realizados dois experimentos com o objetivo de avaliar a influência da época de colheita, condicionamento térmico e armazenamento sobre o comportamento germinativo de sementes de fáfia. No experimento I avaliou-se o efeito da época de colheita das sementes sobre a germinação. Foram realizadas quatro colheitas quinzenais de sementes (tratamentos) a partir dos 146 dias após o plantio das mudas no campo. A avaliação dos efeitos dos tratamentos foi realizada quanto à porcentagem de germinação das sementes (G\%) e o índice de velocidade de germinação (IVG). No experimento II avaliou-se o efeito da interação entre tipos de semente (recém-colhidas e armazenadas) e tratamentos de condicionamento térmico sobre a germinação das mesmas (T1= água destilada, $\mathrm{T} 2=$ condicionamento térmico a $5^{\circ} \mathrm{C}$ por 2 dias + água destilada e $\mathrm{T} 3=$ condicionamento térmico a $5^{\circ} \mathrm{C}$ por 5 dias + água destilada). Concluiu-se que a melhor época para a colheita das sementes de fáfia foi aos 191 dias após o plantio das mudas no campo. O condicionamento térmico das sementes com baixa temperatura reduziu a G\% e o IVG. Embora tenham apresentado porcentagem de germinação reduzida (57\%), as sementes de fáfia toleraram o armazenamento no escuro em condições de laboratório por dois anos.

Palavras-chave: comportamento germinativo; Pfaffia glomerata (Spreng.) Pedersen; qualidade fisiológica.

\section{GERMINATION OF FAFIA: INFLUENCE OF HARVEST TIME, THERMIC CONDITIONING AND STORAGE}

\begin{abstract}
Pfaffia glomerata (Spreng.) Pedersen is a popular medicinal specie knolled by "fafia" or "brazilian ginseng", due to the shape of its roots. Since this specie is wild and there is commercial interest on it, studies about the seeds physiological and physic quality and information related to germination physiology are demanded. Two experiments were conducted to evaluate the influence of harvest time, thermic conditioning and storage upon the germinative behavior of fafia. In the first experiment it was evaluated the effect of the seed's harvest time on germination. It were done four quinzenal seeds harvest (treatments) from the 146 days after the settling in field. The treatments effects was evaluated by the germination percentage (G\%) and germination speed index (GSI). In the second study it was evaluated the interaction effect between kind of seed (recently harvested and stored) and thermic conditioning treatments upon the seed germination (T1= distillated water, $\mathrm{T} 2=$ thermic conditioning in $5^{\circ} \mathrm{C}$ during 2 days + distillated water and $\mathrm{T} 3=$ thermic conditioning in $5^{\circ} \mathrm{C}$ during 5 days + distillated water). It was concluded that the best time to harvest fafia seeds was in the 191 days after the seedling settling in field. The seeds termic conditioning with low temperatures reduced G\% and GSI. Though fafia seeds have showed a reduced germination percentage $(57 \%)$, the same tolerated the storage in the dark on laboratory conditions during two years.

Keywords: germinative behavior; Pfaffia glomerata (Spreng.) Pedersen; physiological quality.
\end{abstract}




\section{INTRODUÇÃO}

A espécie Pfaffia glomerata (Spreng.) Pedersen - Amaranthaceae, é uma planta perene, conhecida pelo nome popular de "ginseng brasileiro", por causa do formato das raízes. 0 interesse comercial da espécie está nas raízes tuberosas que são usadas na medicina popular no Brasil como antirreumáticas, anti-inflamatórias, analgésicas (NICOLOSO, 2001), anti-tumorais, anti-diabetes e tônico afrodisíaco (MAGALHÃES, 2000) e em doenças relacionadas à memória, estresse e envelhecimento (LORENZI; MATOS, 2002). Estudos recentes têm confirmado essa eficiência, o que despertou a atenção de povos asiáticos e europeus, tornando a exportação destas espécies cada vez maior (CORRÊA JUNIOR et al., 2008).

A maior parte da produção é obtida por extrativismo, principalmente na região noroeste do estado do Paraná e vendida aos atacadistas de plantas medicinais que as revende para o mercado interno e externo (MONTANARI JUNIOR, 2002). Um dos caminhos para se amenizar a pressão exercida pelo extrativismo sobre a espécie $P$. glomerata é cultivá-la. Para isso é preciso iniciar estudos que possam auxiliar seu cultivo com base em pesquisas agronômicas, visando à produção de matéria prima com qualidade e em quantidade (CORRÊA JUNIOR et al., 2008). Atualmente vem sendo dada importância cada vez maior aos estudos sobre as qualidades fisiológicas e físicas das sementes de espécies medicinais ainda não domesticadas, bem como informações no que diz respeito à fisiologia da germinação (FARON et al., 2004; DOUSSEAU et al., 2008; SCALON et al., 2009).

O conhecimento das condições ideais para a germinação da semente de determinada espécie é de fundamental importância, principalmente, pelas repostas diferenciadas que ela pode apresentar em função de diversos fatores, como viabilidade, dormência, condições de ambiente, envolvendo água, luz, temperatura, oxigênio e ausência de agentes patogênicos, associados ao tipo de substrato para a germinação (BRASIL, 2009; CARVALHO; NAKAGAWA, 2000). Observações preliminares sobre condições de germinação de $P$. glomerata mostraram que as sementes são fotoblásticas neutras, não apresentam dormência e não necessitam da adição de ácido giberélico $\left(\mathrm{GA}_{3}\right)$ para germinar (RENNER et al., 2007). Embora as sementes apresentem fotoblastismo neutro, na presença de luz a germinação é significativamente aumentada, sugerindo que a luz estimula reações metabólicas mais rápidas que culminam em maior velocidade de desenvolvimento das células do eixo embrionário (SCALON et al., 2009).

Outro fator importante para ser estudado é o armazenamento das sementes. Como a produção é limitada no tempo, o estudo do comportamento das sementes durante o armazenamento destas para posterior produção de mudas é de fundamental importância, pois, quando conservadas por determinados períodos e condições, podem perder a viabilidade (MALAVASI, 1988). Tratamentos como o condicionamento fisiológico de sementes podem resultar em benefícios como germinação mais rápida e sincronizada no tempo. condicionamento fisiológico pode ser empregado em sementes recém colhidas ou armazenadas, através de hidratação controlada e préresfriamento (condicionamento térmico) das sementes, dentre outros (MARCOS FILHO, 2005).

De acordo com Renner et al. (2007), o pré-resfriamento em sementes de fáfia reduziu a porcentagem de germinação, porém não interferiu no tempo médio de germinação. Entretanto, os autores destacam que, devido à alta variabilidade 
genética existente em populações originadas de sementes, estes resultados não são conclusivos. Como a espécie não apresenta dormência, é possível que o pré-resfriamento ou condicionamento térmico atue como um período de ativação lento do metabolismo colaborando para a retomada da síntese de mecanismos de reparo que ocorrem no início do processo de germinação (BEWLEY; BLACK, 1994), agindo assim, como um tratamento de condicionamento fisiológico (MARCOS FILHO, 2005).

Quanto à maturidade, relatam Carvalho e Nakagawa (2000) que as sementes as quais não se encontram completamente maduras podem germinar, não resultando, contudo, em plântulas tão vigorosas como aquelas colhidas no ponto certo. Isto porque as sementes maduras apresentam um desenvolvimento físico e fisiológico que Ihes garantem um máximo de expressão de vigor.

Diante do exposto, o objetivo deste trabalho foi verificar a influência da época de colheita, condicionamento térmico e do armazenamento sobre o comportamento germinativo de Pfaffia glomerata (Spreng.) Pedersen.

\section{MATERIAL E MÉTODOS}

Os experimentos foram conduzidos no Laboratório de Sementes da Faculdade de Agronomia, Campus II, da Universidade do Oeste Paulista (UNOESTE), em Presidente Prudente/SP, no período de setembro a outubro de 2008. Foram realizados dois experimentos, um para avaliar o efeito da época de colheita das sementes de fáfia e outro para avaliar a germinação das sementes submetidas ao condicionamento térmico e armazenamento.

\section{Primeiro experimento}

O lote de sementes de Pffafia glomerata (Spreng) Pedersen que originou as plantas matrizes foi obtido por doação pelo Centro Pluridisciplinar de Pesquisas Químicas, Biológicas e Agrícolas - UNICAMP. Após a germinação das sementes e formação das mudas, o transplante para o campo foi realizado no Horto de Plantas Medicinais da Universidade do Oeste Paulista (UNOESTE), no campus de Agrárias (Campus II), localizada em Presidente Prudente SP, cujas características são de latitude $22^{\circ} 07^{\prime} 04^{\prime \prime} \mathrm{S}$; longitude $51^{\circ} 22^{\prime} 05^{\prime \prime} \mathrm{W}$ e altitude de 435,5 m. O clima é, pela classificação de Köppen, Aw mesotérmico, com verões quentes e invernos secos. O solo é classificado como Argiloso Vermelho-Amarelo, Eutrófico, de textura arenosa/média (EMBRAPA, 2006).

O plantio das mudas no campo foi realizado no mês de abril, após 2 meses de crescimento em casa de vegetação (60 mudas no total). Foram coletadas amostras do solo do local de condução do experimento (camada $0-20 \mathrm{~cm}$ ), obtendo-se os seguintes resultados: $\mathrm{pH}\left(\mathrm{CaCl}_{2}\right)$ 5,1; $7 \mathrm{~g} \mathrm{dm}^{-3}$ de MO; $17 \mathrm{mg} \mathrm{dm}^{-3}$ de $P_{\text {resina }} ; 19$ mmol $_{\mathrm{c}} \mathrm{dm}^{-3}$ de H+Al; 2,3 mmol $_{\mathrm{c}} \mathrm{dm}^{-3}$ de K; 12 $\mathrm{mmol}_{\mathrm{c}} \mathrm{dm}^{-3}$ de Ca; $4 \mathrm{mmol}_{\mathrm{c}} \mathrm{dm}^{-3}$ de $\mathrm{Mg} ; 37 \mathrm{mmol}_{\mathrm{c}}$ $\mathrm{dm}^{-3}$ de capacidade de troca de cátions; $50 \%$ de saturação por bases ; $796 \mathrm{~g} \mathrm{~kg}^{-1}$ de areia; $64 \mathrm{~g} \mathrm{~kg}$ ${ }^{1}$ de silte; $140 \mathrm{~g} \mathrm{~kg}^{-1}$ de argila. A adubação básica do solo foi realizada com 2,5 litros de esterco bovino curtido por cova. Utilizou-se também aproximadamente $250 \mathrm{mg}$ de pó de carvão nas covas, visando o controle de nematóides. O espaçamento adotado foi de 1,0 x 1,0m.

O pleno florescimento das plantas (presença de inflorescências nos ramos principal e laterais) ocorreu em agosto. Foram realizadas quatro colheitas quinzenais de sementes, nas datas de 09/09/2008, 24/09/2008, 09/10/2008 e 24/10/2008; ou seja, aos 146, 161, 176 e 191 dias após o plantio das mudas no campo (DAP), respectivamente. Foram escolhidas aleatoriamente 10 plantas para a retirada de sementes, dentro de cada época de colheita, 
visando contemplar a variabilidade natural das plantas no campo. Após cada colheita, as sementes foram reunidas e levadas para 0 Laboratório de Sementes, onde as mesmas foram limpas, para separação das inflorescências, com auxílio de peneiras, pinças e soprador de sementes, tipo South Dakota.

Os tratamentos foram estabelecidos pelas quatro épocas de colheita. As sementes foram distribuídas em 5 repetições por tratamento, sendo cada repetição composta por 40 sementes, distribuídas sobre papel para germinação umedecido com $20 \mathrm{~mL}$ de água destilada. As condições da câmara de germinação foram de luz branca fluorescente contínua e temperatura média de $22^{\circ} \mathrm{C} \pm 2$, conforme metodologia descrita por Renner et al. (2007). O delineamento experimental foi inteiramente casualizado.

A contagem das plântulas foi diária até 0 15ํ dia após a semeadura (DAS). A avaliação dos efeitos dos tratamentos sobre a germinação das sementes foi realizada quanto à porcentagem de germinação das sementes (G\%), considerando-se a protrusão da raiz primária com $0,5 \mathrm{~cm}$. O índice de velocidade de germinação (IVG) foi calculado conforme Nakagawa (1999). Os resultados foram submetidos à análise de variância (teste F), e as médias comparadas pelo teste Tukey, ao nível de $5 \%$ de probabilidade através do software Sisvar.

\section{Segundo experimento}

Foram utilizados dois lotes de sementes de Pffafia glomerata (Spreng) Pedersen. As sementes novas (frescas) foram provenientes da colheita realizada aos 191 dias após o plantio das mudas no campo ( $4^{a}$ época de colheita do primeiro experimento). As sementes armazenadas foram provenientes do mesmo lote doado pelo Centro Pluridisciplinar de Pesquisas Químicas, Biológicas e Agrícolas -UNICAMP), cujo armazenamento ocorreu por um período de dois anos, em condições de escuro e temperatura ambiente $\left(25^{\circ} \mathrm{C} \pm 3\right)$.

Os dois lotes de sementes (recémcolhidas e armazenadas) foram submetidos a três tratamentos: T1 - água destilada (controle); T2 condicionamento térmico a $5^{\circ} \mathrm{C}$ por 2 dias + água destilada e T3 - condicionamento térmico a $5^{\circ} \mathrm{C}$ por 5 dias + água destilada. As sementes foram mantidas em geladeira durante os períodos de condicionamento, sendo posteriormente realizadas as semeaduras nas caixas plásticas "gerbox". As condições de germinação utilizadas, a contagem das plântulas e a expressão dos resultados foram as mesmas já descritas no primeiro experimento. A contagem das plântulas foi realizada diariamente, até completar 15 dias após a semeadura (DAS).

Estabeleceu-se 0 delineamento experimental inteiramente casualizado, com esquema fatorial $2 \times 3$, sendo dois tipos de sementes (novas e armazenadas) e três condições de condicionamento térmico (ausência de condicionamento, condicionamento por 2 dias e condicionamento por 5 dias). Os resultados foram submetidos à análise de variância (teste F), e as médias comparadas pelo teste Tukey, ao nível de $5 \%$ de probabilidade de erro através do software Sisvar.

\section{RESULTADOS E DISCUSSÃO}

\section{a) Efeito da época de colheita sobre a germinação}

A porcentagem de germinação e o índice de velocidade de germinação das sementes de fáfia em função das diferentes épocas de colheita são apresentados na Tabela 1. Observa-se que a época de coleta das sementes influenciou significativamente a porcentagem de germinação, havendo aumento crescente nesta variável conforme se aumentou o tempo de coleta e, portanto, o grau de maturidade da semente. 
Tabela 1. Porcentagem de germinação (G\%) e índice de velocidade de germinação (IVG) de sementes de fáfia - Pfaffia glomerata (Spreng.) Pedersen, colhidas aos 146, 161, 176 e 191 dias após o plantio das mudas no campo (DAP). Presidente Prudente, 2009.

\begin{tabular}{ccc}
\hline Época de colheita & $\mathrm{G} \%$ & $\mathrm{IVG}$ \\
\hline 146 DAP & $30,5 \mathrm{~d}^{1}$ & $14,4 \mathrm{~d}$ \\
161 DAP & $45,5 \mathrm{c}$ & $19,5 \mathrm{c}$ \\
176 DAP & $56 \mathrm{~b}$ & $28,06 \mathrm{~b}$ \\
191 DAP & $80,5 \mathrm{a}$ & $33,8 \mathrm{a}$ \\
\hline $\mathrm{F}$ & $129,92{ }^{\star *}$ & $84,955^{\star *}$ \\
$\mathrm{CV}(\%)$ & 7,76 & 8,82 \\
\hline${ }^{1}$ Médias seguidas da mesma letra nas colunas não diferem entre si pelo Teste Tukey $(\mathrm{p}<0,05)$.
\end{tabular}

$\mathrm{Na}$ Tabela 1 constata-se que quanto mais tarde foi à época de colheita, maior foi a velocidade de germinação das sementes de fáfia, comprovando que o tempo de maturação das mesmas é fator determinante para a expressão do vigor, neste trabalho expresso em função do IVG. Na maturidade fisiológica, as sementes atingem o máximo de germinação e vigor, devido à formação completa dos sistemas bioquímico, morfológico e estrutural (SILVA et al., 2009 ; NAKADA et al., 2011). Dessa forma, o estabelecimento do melhor estágio de colheita das sementes visa à obtenção de sementes que apresentem o máximo rendimento e consequente produtividade.

O padrão de coloração das sementes maduras (marrom acastanhado) não apresentou alterações entre as diferentes épocas de colheita. Ribeiro e Pereira (1994) destacam que as sementes de fáfia têm formato cordiforme e que as mesmas possuem coloração verde-clara quando imaturas e marron- acastanhada quando maduras (prontas para serem colhidas). Desta forma, a coloração das sementes, bem como outras características observadas no fruto, não permitiu a definição de uma característica que pudesse ser indicativa do ponto de colheita, como indicam Carvalho e Nakagawa, 2000.

Quando são examinadas em conjunto as características físicas e fisiológicas da maturação das sementes, destaca-se o fato de que, aparentemente, germinação, vigor e conteúdo de matéria seca chegam a um ponto máximo, aproximadamente, ao mesmo tempo. A fixação, em termos de dias, da maturidade fisiológica após ocorrência de um dado evento, como semeadura, emergência de plântulas, florescimento, frutificação, etc., pode apresentar diferenças para uma dada espécie e cultivar, em função das variações do meio ambiente. Há, portanto, a necessidade, sempre que possível, de se detectar características de mais fácil observação, que definam com razoável precisão esta maturidade (CARVALHO; NAKAGAWA, 2000).

\section{b) Efeito do condicionamento térmico e armazenamento das sementes sobre a germinação.}

A germinação das sementes de fáfia, em todos os tratamentos, ocorreu entre o terceiro e o quinto dia após a semeadura, com valores em torno de 53 a $79 \%$, sendo que as sementes novas apresentaram taxas de germinação superiores às armazenadas, independente dos tratamentos aplicados (Tabela 2). Valores semelhantes de germinação para esta mesma espécie foram observados por Mendes et al. (2004) e Renner et al. (2007). No entanto, os dados deste experimento discordam dos resultados obtidos por Scalon et al. (2009), os quais relataram baixa germinação para a fáfia, destacando a necessidade de imersão das sementes em 
agentes químicos para acelerar o processo germinativo.

Tabela 2. Porcentagem de germinação (G\%) de sementes novas e armazenadas de fáfia submetidas a diferentes tratamentos (T1- controle; T2- condicionamento térmico a $5^{\circ} \mathrm{C}$ por 2 dias e T3- condicionamento térmico a $5^{\circ} \mathrm{C}$ por 5 dias). Presidente Prudente, 2009.

\begin{tabular}{lcccc}
\hline \multicolumn{1}{c}{ G\% } & T1 & T2 & T3 & Média \\
\hline Semente nova & 79 & 75 & 66 & $73,3 \mathrm{a}^{1}$ \\
Semente armazenada & 57 & 53 & 53 & $54,2 \mathrm{~b}$ \\
& & & & \\
\hline Média & $67,8 \mathrm{~A}$ & $64 \mathrm{AB}$ & $59,5 \mathrm{~B}$ & \\
& & & & \\
\hline F (tipo semente) & $96,91^{*}$ & & & \\
F (condicionamento) & $6,28^{*}$ & & \\
CV (\%) & 7,4 & & \\
\hline iddas da mesma letra, minúscula nas colunas e maiúscula nas linhas, não diferem entre si pelo Teste Tukey $(p<0,05)$.
\end{tabular}

Observou-se que as sementes novas (recém-colhidas) de fáfia que passaram pelo condicionamento térmico por 2 dias (T2) apresentaram porcentagem de germinação semelhante às sementes controle (T1). Entretanto, o tratamento com condicionamento térmico por 5 dias (T3) resultou em diminuição significativa na germinação das sementes novas. Sampaio (2002) destacou que temperaturas muito altas ou muito baixas costumam inibir a germinação.

Para as sementes armazenadas, não houve diferença entre os tratamentos aplicados com relação à porcentagem de germinação. Mas é interessante observar que o período e as condições de armazenamento, apesar de terem resultado em decréscimo de $70 \%$ para $50 \%$, em média, na germinação, ainda possibilitaram um bom potencial germinativo das sementes de fáfia, revelando que a espécie tolerou 0 armazenamento, podendo ser considerada, quanto à longevidade, de vida longa. Souza et al. (2007) obtiveram resultado semelhante ao trabalhar com sementes de camomila, onde o potencial de germinação e o índice de velocidade de germinação das sementes foram mantidos nos dois primeiros anos de armazenamento em câmara fria.

Variações de longevidade, entre sementes de espécies e cultivares, geralmente estão associadas ao desempenho de sementes recalcitrantes e ortodoxas, de vida curta e longa, respectivamente. A abordagem referente os efeitos do ambiente de armazenamento sobre a deterioração das sementes deve considerar a ação conjunta da água e da temperatura. Portanto, para as sementes ortodoxas (tolerantes ou resistentes à desidratação), como se supõe ser o caso da fáfia, a manutenção do potencial fisiológico durante o período de armazenamento é favorecida por ambientes de baixa umidade relativa do ar associada a baixas temperaturas (MARCOS FILHO, 2005).

Com relação ao índice de velocidade de germinação (IVG), nas sementes novas houve diminuição nos valores à medida que se aumentou o tempo de condicionamento térmico (Tabela 3), indicando que este tipo de condicionamento não foi favorável às sementes. Estes resultados concordam, em parte, com aqueles obtidos por Renner et al. (2007), onde o pré-resfriamento reduziu a germinação desta 
espécie, porém não aumentou o tempo médio de germinação. Neste trabalho, a diminuição do IVG indica que a germinação foi mais lenta e, portanto, houve aumento do tempo necessário para a germinação das sementes pré-tratadas. Já para as sementes armazenadas não houve diferença no IVG entre os 3 tratamentos (Tabela 3).

Tabela 3. Índice de velocidade de germinação (IVG) de sementes novas e armazenadas de fáfia submetidas a diferentes temperaturas (T1- controle; T2- pré-resfriamento a $5^{\circ} \mathrm{C}$ por 2 dias e T3- préresfriamento a $5^{\circ} \mathrm{C}$ por 5 dias). Presidente Prudente, 2009.

\begin{tabular}{lccc}
\hline & T1 & T2 & T3 \\
& & & \\
\hline Semente nova & $10,00 \mathrm{Aa}^{1}$ & $8,42 \mathrm{Ba}$ & $6,85 \mathrm{Ca}$ \\
Semente armazenada & $7,11 \mathrm{Ab}$ & $6,60 \mathrm{Ab}$ & $6,5 \mathrm{Aa}$ \\
& & \\
F (interação) & $5,27^{\star \star}$ & \\
CV (\%) & 10,16 & \\
\hline idas da mesma letra, minúscula nas colunas e maiúscula nas linhas, não diferem entre si pelo Teste Tukey $(p<0,01)$.
\end{tabular}

Quando se realiza a comparação do mesmo tratamento entre as duas sementes (novas e armazenadas), verifica-se que para os tratamentos T1 (controle) e T2 (condicionamento térmico a $5^{\circ} \mathrm{C}$ por 2 dias) houve diminuição no IVG das sementes armazenadas, indicando germinação mais lenta, sendo que para o T3 esse resultado não foi observado. Ao contrário do que se esperava, o condicionamento térmico não resultou em condicionamento fisiológico, como descrito por Marcos Filho (2005). Segundo este, entre os principais efeitos do condicionamento estão a aceleração da velocidade de germinação, a sincronização deste processo, a redução de injúrias durante a embebição, a indução de tolerância a estresse após a semeadura, a diminuição do tempo para a formação de mudas e na superação de dormência de várias espécies.

Porém, a utilização da temperatura de $5^{\circ} \mathrm{C}$ pode ter produzido injúria, relacionada à diminuição da taxa de reações enzimáticas e da energia de ativação necessária para diferentes reações conduzindo a efeito diferencial da temperatura, dependendo da rota considerada, o que pode ter desfavorecido a germinação ou sua velocidade (BEWLEY; BLACK, 1994).

Como o condicionamento térmico também pode ser associado com quebra de dormência, os resultados obtidos nesta pesquisa permitem adicionalmente concordar Renner et al. (2007) que afirmaram a ausência de dormência para a espécie.

\section{CONCLUSÃO}

Concluiu-se que a melhor época para a colheita das sementes de fáfia foi aos 191 dias após o plantio das mudas no campo. O condicionamento térmico das sementes de fáfia com baixa temperatura reduziu a porcentagem de germinação e também o índice de velocidade de germinação. Embora tenham apresentado porcentagem de germinação reduzida (57\%), as sementes de fáfia toleraram o armazenamento no escuro e em condições de laboratório, por dois anos. 


\section{REFERÊNCIAS}

BRASIL. Ministério da Agricultura, Pecuária e Abastecimento. Secretaria de Defesa Agropecuária. Regras para Análise de Sementes. Brasília: MAPA/ACS, 2009.

BEWLEY, J. D.; BLACK, M. Seeds: physiology of development and germination. 2. ed. New York: Plenum, 1994.

CARVALHO, N. M.; NAKAGAWA, J. Sementes: ciência, tecnologia e produção. 4. ed. Jaboticabal: Funep, 2000.

CORRÊA JUNIOR, C. et al. Sazonalidade na produção de raízes e teor de p-ecdisona em acessos de fáfia. Horticultura Brasileira, v. 26, n. 3, p. 393-97, 2008.

DOUSSEAU, S.; ALVARENGA, A. A.; ARANTES, L. O.; OLIVEIRA, D. M.; NERY, F. C. Germinação de sementes de tanchagem (Plantago tomentosa Lam.): influência da temperatura, luz e substrato. Ciência e Agrotecnologia, v. 32, n. 2, p. 438-43, $2008 . \quad$ http://dx.doi.org/10.1590/S141370542008000200014

EMBRAPA. Sistema brasileiro de classificação de solos. Brasília: Embrapa Produção de Informações (SPI), 1999.

FARON, M. L. B.; PERECIN, M. B.; LAGO, A. A.; BOVI, O. A.; MAIA, N. B. Temperatura, nitrato de potássio e fotoperíodo na germinação de sementes de Hypericum perforatum L. e $H$. brasiliense Choisy. Bragantia, v. 63, n. 2, p. 193-9, 2004. http://dx.doi.org/10.1590/S0006-

87052004000200004

LORENZI, H.; MATOS, F. J. A. Plantas medicinais no Brasil: nativas e exóticas. Nova Odessa: Plantarum, 2002.

MAGALHÃES, P. M. Agrotecnologia para o cultivo da fáfia. In: Martínez, J. V.; Bernal, H. Y.;
Cáceres, A. (eds.). Fundamentos de agrotecnologia de cultivo de plantas medicinales ibero americanas. Convenio Andres Bello- CYTED, 2000. p. 323-32.

MALAVASI, M. M. Germinação de sementes. In: PIÑA-RODRIGUES, F. C. M. (coord.) Manual de análises de sementes florestais. Campinas: Fundação Cargil, 1988. p. 44-67.

MARCOS FILHO, J. Fisiologia de sementes de plantas cultivadas. Piracicaba: FEALQ, 2005.

MENDES, J.; LOPES, J. C.; RENNER, G. D. R. Análise comparativa dos meios MS e de Dyer na germinação de Pfaffia glomerata e Lippia alba. Caderno de Iniciação à Pesquisa da Univille, v.6, p.153-6, 2004.

MONTANARI JUNIOR, I. Exploração econômica de plantas medicinais da Mata Atlântica. In: SIMÕES, L. L.; LINO, C. F. (orgs.). Sustentável Mata Atlântica: a exploração de seus recursos florestais. São Paulo: SENAC, 2002. p. 35-54.

NAKADA, P. G.; OLIVEIRA, J. A.; MELO, L. C.; GOMES, L. A. A.; VON PINHO, E. V. R. Desempenho fisiológico e bioquímico de sementes de pepino nos diferentes estádios de maturação. Revista Brasileira de Sementes, v. 33, n. $1, \quad$ p. $113-122,2011$. http://dx.doi.org/10.1590/S010131222011000100013

NAKAGAWA, J. Testes de vigor baseados no desempenho de plântulas. In: KRZYZANOWSKI, F. C.; VIEIRA, R. D.; FRANÇA NETO, J. B. (eds.). Vigor de sementes: conceitos e testes. Londrina: ABRATES, 1999. p. 1-24.

NICOLOSO F. T.; ERIG, A. C.; MARTINS, C. F.; RUSSOWSKI, D. Micropropagação do ginseng brasileiro [Pfaffia glomerata (Spreng.) Pedersen]. Revista Brasileira de Plantas Medicinais, v. 3, n. 2, p. 11-8, 2001. 
RENNER, G. D. R.; CAMACHO, F.; PEIXE, S. Ação da temperatura, ácido giberélico e luz na germinação de sementes de fáfia - Pfaffia glomerata (Spreng.) Pedersen. Semina: Ciências Agrárias, v. 28, n. 3, p. 349-54, 2007.

RIBEIRO, P. G. F.; PEREIRA, E. F. Influência do método de propagação e tipo de solo na produção de raízes de fáfia (Pfaffia glomerata). In: SIMPÓSIO DE PLANTAS MEDICINAIS DO BRASIL, 13, 1994, Fortaleza. Anais... Fortaleza: FINEP/CNPq, 1994.

SAMPAIO, E. S. Fisiologia vegetal: teoria e experimentos. Ponta Grossa: UEPG, 2002.

SCALON, S. P. Q.; MUSSURY, R. M.; ROSA, G. T. S.; MORAES, K. C.; SCALON FILHO, H. Enraizamento e germinação na propagação de Pfaffia glomerata (Spreng.) Pedersen (ginseng-brasileiro). Ciência e Agrotecnologia, v. 33, n. 5, p. 1249-54, 2009. http://dx.doi.org/10.1590/S141370542009000500007

SILVA, R. F.; ARAÚJO, E. F.; VIGGIANO, J. Extração de sementes de frutos carnosos de hortaliças. In: NASCIMENTO, W.M. Tecnologia de sementes de hortaliças. Brasília: EMBRAPA Hortaliças, 2009.

SOUZA, J. R. P.; TAKAHASHI, L. S. A.; YOSHIDA, A. E.; GUIRAUD, M. C.; ROCHA, J. N. Tempo de armazenamento e temperatura na porcentagem e velocidade de germinação das sementes de camomila. Ciência Rural, v. 37, n. 4, p. 982-6, 2007.

http://dx.doi.org/10.1590/S0103-

84782007000400010 